\title{
The Prevalence and Associated Factors of Short Sleep Duration Among Nurses in Tertiary Public Hospitals in China: Findings from a National Survey
}

\author{
Dan Liu' \\ Yinuo $\mathrm{Wu}^{2}$ \\ Feng Jiang ${ }^{3}$ \\ Yuanli Liu' \\ Yi-Lang Tang ${ }^{4,5}$
}

'School of Health Policy and Management, Chinese Academy of Medical Sciences \& Peking Union Medical College, Beijing, People's Republic of China; ${ }^{2}$ Chinese Academy of Medical Sciences \& Peking Union Medical College, Beijing, People's Republic of China; ${ }^{3}$ Hospital Management and Evaluation Research Center, Institute of Healthy Yangtze River Delta, Shanghai Jiao Tong University, Shanghai, People's Republic of China; ${ }^{4}$ Department of Psychiatry and Behavioral Sciences, Emory University, Atlanta, GA, USA; ${ }^{5}$ Atlanta VA Medical Center, Atlanta, GA, USA
Correspondence: Yuanli Liu School of Health Policy and Management, Chinese Academy of Medical Sciences \& Peking Union Medical College, No. 3 Dong Dan San Tiao, Dongcheng District, Beijing, People's Republic of China Email liuyl_fpo@I26.com
Background: Sleep is an essential component of health and well-being. Short sleep duration may negatively affect nurses' health and patients' safety.

Objective: To investigate the sleep duration and subjective satisfaction with sleep duration among nurses in tertiary public hospitals in China and to explore the associated factors.

Methods: This cross-sectional study was conducted between December 18 and 31, 2017 in 136 major public hospitals from 31 provinces in mainland China. An online anonymous questionnaire was delivered through WeChat. Totally 27,575 nurses completed the survey.

Results: The response rate was $95.46 \%$. The mean reported total sleep duration was 6.67 \pm 0.97 hours per day. About $46.87 \%(\mathrm{n}=12,924)$ reported having short sleep duration (SSD, less than 7 hours per day), and $27.63 \%(n=7618)$ were not satisfied with their sleep duration. In the SSD group, $45.67 \%(n=5902)$ were dissatisfied with their sleep duration. SSD was significantly associated with sociodemographic factors, including an older age, having more than one child, being divorced or separated, and job-related factors, including longer working hours, more night shifts and heavy workload.

Conclusion: Nearly half of the nurses in the public hospitals in China reported sleeping less than 7 hours, and more than one quarter were dissatisfied with their sleep duration. Interventions are needed to improve Chinese nurses' sleep, including reducing working hours, night shifts or workload.

Keywords: short sleep duration, prevalence, satisfaction, nurse, tertiary public hospitals

\section{Background}

Sleep is a critical determinant for human health and well-being. ${ }^{1}$ As sleep duration is related to subjective sleep quality and subjective well-being, ${ }^{2}$ a recent consensus statement suggests that general adults should have no less than 7 hours of sleep per night. ${ }^{3}$ Short sleep duration (SSD), defined as less than 7 hours of sleep per night, is associated with adverse health outcomes and increased medical costs, ${ }^{4,5}$ as SSD affects basic patterns of behavior that may negatively impact health and interpersonal relationships. ${ }^{6}$ Epidemiological evidence suggests that SSD is associated with mortality and a wide range of adverse health outcomes, including increased risks of hypertension, diabetes, depression, heart attack, and stroke. ${ }^{7-10}$ In order to implement appropriate strategies to reduce the harmful consequences caused by SSD, it is important to understand its risk factors. Several existing studies have identified a few factors to be associated with SSD, including female sex, older age, divorced or separated marital status, lower educational level, and psychiatric conditions. ${ }^{11-13}$ 
Previous reports also showed SSD may negatively affect nurses' health and patients' safety. ${ }^{14}$ One study found that the SSD prevalence was $75.9-76 \%$ in Thai nurses, and the SSD group experienced more fatigue and occupational errors. ${ }^{15,16}$ Another study included 2518 female nurses in Brazil and found $48.6 \%$ of them reported SSD, with poor self-rated health status. ${ }^{17}$ A study in China examined 799 nurses from three hospitals, and they found the total sleep time of nurses was $6.1 \pm 1.1$ hours per day. In short, SSD might be common in Chinese Nurses. ${ }^{18}$ However, the prevalence of short sleep duration and its correlates in Chinese nurses have not been examined.

This study aimed to determine (a) the sleep duration, (b) SSD prevalence and (c) the associated factors of SSD among nurses in tertiary public hospitals in China.

\section{Materials and Methods}

\section{Study Design and Samples}

The study was one part of the China's Healthcare Improvement Initiative Survey in 2017. ${ }^{19}$ The National Health Commission of China approved and supported this project. The project was conducted between December 18 and 31, 2017. We selected 136 tertiary public hospitals across 31 provinces in mainland China. All target hospitals were contacted individually and the survey background, significance, instructions, and survey pathway (not actual questions) were provided.

According to employees' ID codes, 220 nurses were sampled through a systematic sampling method in each participating hospital. ${ }^{19}$ We conducted the survey anonymously through WeChat, a popular social media application in mainland China. The questionnaires were answered anonymously by participants on their cell phones or computers.

\section{Ethics Statement}

This study was conducted in accordance with the Declaration of Helsinki. The Ethics Committee (IRB) of the School of Public Health of Peking Union Medical College approved the study protocol. All participants provided written informed consent before they can respond to the questionnaires.

\section{Measures}

Sleep duration was evaluated using a self-report question. ${ }^{20}$ "In the previous month, how many hours do you sleep in a typical night during the working week?" We also assessed the sleep duration satisfaction (How satisfied are you with your sleep duration), using a 3-point Likert scale (1-dissatisfied, 2-neutral, 3-satisfied). Workload was evaluated using a self-report 3-point Likert scale (1-mild, 2-moderate, 3-heavy). The Cronbach's alpha value of these items was larger than 0.70 , suggesting a good reliability. ${ }^{21}$

Additionally, we also collected participants' sociodemographic data, including age, gender, marital status, number of children, education, region; as well as job-related factors, including department, administration position, number of night shifts per month, and hospital type. In these hospitals, nurses generally worked in shifts, including day shifts (8am to $4 \mathrm{pm}$ ), evening shifts (4pm to $12 \mathrm{am}$ ), and night shifts (12am to $8 \mathrm{am})$ and they often rotate according to a weekly schedule.

\section{Statistical Analysis}

Descriptive analyses were conducted for the variables. According to the cut-off point, participants were divided into SSD group ( $<7$ hours) and non-SSD group ( $\geq 7$ hours). Other appropriate cut-off points were selected to ensure subgroups were balanced in variables.

We used the multiple logistic regression to examine the association between SSD and demographic/job-related factors. These statistical analyses were conducted through Stata 15 (StataCorpLP, College Station, TX, USA). We defined the statistical significance as $p<0.05$, and all of the tests were two-sided.

\section{Results}

\section{Description of Sample Characteristics and Related Factors}

Totally 29,920 nurses were invited to participate in the survey, and 27,575 completed, with a response rate of $95.46 \%$. Table 1 demonstrated their sociodemographic characteristics.

\section{Description of Sleep Duration and Satisfaction}

The average sleep duration was $6.67 \pm 0.97$ hours per day. Nearly half of nurses $(n=12,924,46.87 \%)$ reported SSD. In all of participants, $27.63 \%(n=7618)$ were dissatisfied with their sleep duration. In SSD group, $45.67 \%(\mathrm{n}=5902)$ were dissatisfied with their sleep duration. 
Table I Characteristics of Participants $(\mathrm{N}=27,575)$

\begin{tabular}{|c|c|c|}
\hline Characteristic & Frequency & Percentage (\%) \\
\hline \multicolumn{3}{|l|}{ Sex } \\
\hline Male & 690 & 2.50 \\
\hline Female & 26,885 & 97.50 \\
\hline \multicolumn{3}{|l|}{ Age (year) } \\
\hline$\leq 29$ & 12,678 & 45.98 \\
\hline $30-39$ & 10,678 & 38.72 \\
\hline $40-49$ & 3296 & 11.95 \\
\hline$\geq 50$ & 923 & 3.35 \\
\hline \multicolumn{3}{|l|}{ Marital status } \\
\hline Not married & 8616 & 31.25 \\
\hline Married & 18,382 & 66.66 \\
\hline Devoiced or separated & 577 & 2.09 \\
\hline \multicolumn{3}{|l|}{ Children } \\
\hline None & 11,748 & 42.60 \\
\hline One child & 13,593 & 49.29 \\
\hline More than one & 2234 & 8.10 \\
\hline \multicolumn{3}{|l|}{ Education } \\
\hline Associate degree & 7857 & 28.49 \\
\hline Bachelor's degree & 19,132 & 69.38 \\
\hline Master's or doctorate degree & 586 & 2.13 \\
\hline \multicolumn{3}{|l|}{ Working hours } \\
\hline$\leq 40$ hours/week & 19,430 & 70.46 \\
\hline $4 I-44$ hours/week & 1476 & 5.35 \\
\hline 45-48 hours/week & 3298 & 11.96 \\
\hline$>48$ hours/week & 3371 & 12.22 \\
\hline \multicolumn{3}{|l|}{ Department } \\
\hline General medicine & 6780 & 24.59 \\
\hline General surgery & 4914 & 17.82 \\
\hline Gynecology and obstetrics & 3992 & 14.48 \\
\hline General pediatrics & 2215 & 8.03 \\
\hline Emergency medicine & 1509 & 5.47 \\
\hline Internal medicine subspecialty & 5239 & 19.00 \\
\hline General surgery subspecialty & 2926 & 10.61 \\
\hline \multicolumn{3}{|l|}{ Administration position } \\
\hline Yes & 2369 & 8.59 \\
\hline No & 25,206 & 91.41 \\
\hline \multicolumn{3}{|l|}{ Night shifts per month } \\
\hline None & 8947 & 32.45 \\
\hline I-4 shifts & 7414 & 26.89 \\
\hline $5-10$ shits & 9301 & 33.73 \\
\hline$>10$ shifts & 1913 & 6.94 \\
\hline \multicolumn{3}{|l|}{ Hospital type } \\
\hline General Hospitals & II,797 & 42.78 \\
\hline Traditional Chinese Medicine & 6411 & 23.25 \\
\hline
\end{tabular}

(Continued)
Table I (Continued).

\begin{tabular}{|l|c|c|}
\hline Characteristic & Frequency & Percentage (\%) \\
\hline $\begin{array}{l}\text { Maternal and Child Healthcare } \\
\text { Hospitals }\end{array}$ & 9367 & 33.97 \\
\hline Region & & \\
East China & 10,341 & 37.50 \\
Central China & 6944 & 25.18 \\
West China & 10,290 & 37.32 \\
\hline Workload & & \\
Heavy & 10,565 & 38.31 \\
Moderate & 11,317 & 41.04 \\
Mild & 5693 & 20.65 \\
\hline
\end{tabular}

\section{Logistic Regression Analysis of SSD and Associated Factors}

The multivariate logistic regression model demonstrated that nurses who were elder, divorced or separated, having more than one child, longer working hours, working in special departments, more night shifts, heavy workload, and in East China were more likely to suffer SSD (see Table 2).

\section{Discussion}

This study was among the first reports of sleep duration, the prevalence of SSD and its correlates in a very large national sample covering 31 provinces in mainland China.

The mean total sleep time in our study was overall consistent with findings from other studies. ${ }^{16,18}$ The prevalence of SSD in our study is very close to the survey in Brazil, which demonstrated that $48.6 \%$ of nurses had $\mathrm{SSD},{ }^{17}$ but is much lower than in Thailand, in which they found about $76 \%$ nurses slept less than 7 hours. ${ }^{15,16}$ This gap may be due to the differences of the healthcare systems and characteristics of participants. For example, $57.7 \%$ of Thai nurses in the studies were single, ${ }^{15,16}$ while only $31.25 \%$ nurses were not married in our sample. While further studies are needed to understand the gap among different countries.

We found that nearly half of the nurses in SSD group were not satisfied with their sleep duration. While most studies in this area have focused on sleep (quality) satisfaction, ${ }^{22}$ few focused on sleep duration satisfaction. Our survey may provide additional information about sleep assessment in professionals. 
Table 2 Logistic Regression Analysis of SSD

\begin{tabular}{|c|c|c|c|}
\hline Characteristic & Odds Ratio & 95\% Cl (Lower) & 95\% Cl (Upper) \\
\hline Female (ref. male) & 1.14 & 0.97 & 1.34 \\
\hline \multicolumn{4}{|l|}{ Age (ref. $\leq 29)$} \\
\hline $30-39$ & $1.23 * *$ & 1.15 & 1.32 \\
\hline $40-49$ & $1.82 * *$ & 1.64 & 2.01 \\
\hline$\geq 50$ & $1.75 * *$ & 1.50 & 2.04 \\
\hline \multicolumn{4}{|l|}{ Marital status (ref. not married) } \\
\hline Married & 1.01 & 0.93 & 1.10 \\
\hline Devoiced or separated & $1.36 *$ & 1.12 & 1.64 \\
\hline \multicolumn{4}{|l|}{ Children (ref. None) } \\
\hline One & 1.08 & 0.99 & 1.18 \\
\hline More than one & $1.19 *$ & 1.06 & 1.34 \\
\hline \multicolumn{4}{|l|}{ Education(ref. Below bachelor's degree) } \\
\hline Bachelor's degree & 1.03 & 0.97 & 1.09 \\
\hline Master's or doctorate degree & 1.10 & 0.91 & 1.32 \\
\hline \multicolumn{4}{|l|}{ Working hours (ref. $\leq 40$ hours/week) } \\
\hline $4 I-44$ hours/week & $1.15 *$ & 1.03 & 1.29 \\
\hline 45-48 hours/week & $1.26 * *$ & 1.16 & 1.36 \\
\hline$>48$ hours/week & $1.40 * *$ & 1.29 & 1.52 \\
\hline \multicolumn{4}{|l|}{ Department (ref. General pediatrics) } \\
\hline General medicine & $1.19 *$ & 1.07 & 1.32 \\
\hline General surgery & $1.17 *$ & 1.05 & 1.31 \\
\hline Gynecology and obstetrics & $1.23 * *$ & 1.10 & 1.37 \\
\hline Emergency medicine & 1.06 & 0.92 & 1.22 \\
\hline Internal medicine subspecialty & $1.14 *$ & 1.02 & 1.27 \\
\hline General surgery subspecialty & $1.17 *$ & 1.04 & 1.31 \\
\hline Administration position (ref. No) & 1.04 & 0.95 & 1.15 \\
\hline \multicolumn{4}{|l|}{ Night shift per month (ref. No) } \\
\hline I-4 times/month & $1.13 * *$ & 1.05 & 1.21 \\
\hline $5-10$ times/month & $1.47 * *$ & 1.37 & 1.57 \\
\hline$>10$ times/month & $1.80 * *$ & 1.62 & 2.01 \\
\hline \multicolumn{4}{|l|}{ Hospital type (ref. General) } \\
\hline Traditional Chinese Medicine Hospitals & 1.06 & 0.99 & 1.13 \\
\hline Maternal and Child Healthcare Hospitals & 1.04 & 0.98 & 1.11 \\
\hline \multicolumn{4}{|l|}{ Region (ref. West China) } \\
\hline East China & $1.36 * *$ & 1.28 & $\mathrm{I} .44$ \\
\hline Central China & 0.99 & 0.93 & 1.06 \\
\hline \multicolumn{4}{|l|}{ Workload (ref. Mild level) } \\
\hline Moderate & $2.33 * *$ & 2.17 & 2.51 \\
\hline Heavy level & $4.11 * *$ & 3.81 & 4.43 \\
\hline
\end{tabular}

Notes: $*_{p}<0.05, *_{p}<0.001$.

We found that age, marital status, number of children, and job-related factors were significantly associated with SSD, which was consistent with previous reports. ${ }^{23,24}$
Meanwhile the location of hospitals was also an independent significant factor, which suggested other geographical factors may play a role in sleep duration. 


\section{Limitations}

There are several limitations about this study. First, as is the case in almost all cross-sectional studies, the causal relationship of SSD and other factors cannot be established. Second, we did not include the measures of sleep quality, as sleep duration and sleep quality have modest overlap. Third, the sample was from tertiary public hospitals, so the findings may not be generalizable to all nurses in China, especially those working in rural areas. Finally, the instrument in our survey was not a standardized tool, which may be limited in reliability and validity.

\section{Conclusions}

In conclusion, we found that SSD was prevalent among Chinese nurses working in tertiary public hospitals, and nearly half of SSD nurses were dissatisfied with their sleep duration. Hospital administrators and policymakers need to be aware of this important issue. Changes are clearly required to improve the sleep duration of nurses, including reducing working hours, number of night shifts or workload.

\section{Data Sharing Statement}

The datasets used and/or analyzed during the current study are available from the corresponding author on reasonable request.

\section{Disclosure}

The authors declare that they have no competing interests.

\section{References}

1. Institute of Medicine Committee on Sleep M. Research: the national academies collection: reports funded by national institutes of health. In: Colten HR, Altevogt BM, editors. Sleep Disorders and Sleep Deprivation: An Unmet Public Health Problem. Washington (DC): National Academies Press (US). National Academy of Sciences; 2006:2.

2. Lemola S, Ledermann T, Friedman EM, Gamble KL. Variability of sleep duration is related to subjective sleep quality and subjective well-being: an actigraphy study. PLoS One. 2013;8(8):e71292. doi:10.1371/journal.pone.0071292

3. Consensus Conference P, Watson NF, Badr MS, et al. Joint consensus statement of the American Academy of Sleep Medicine and Sleep Research Society on the recommended amount of sleep for a healthy adult: methodology and discussion. Sleep. 2015;38:1161-1183. doi:10.5665/sleep.4886

4. Xie D, Li W, Wang Y, et al. Sleep duration, snoring habits and risk of acute myocardial infarction in China population: results of the INTERHEART study. BMC Public Health. 2014;14(1):531. doi:10.1186/1471-2458-14-531

5. Leger D, Poursain B. An international survey of insomnia: under-recognition and under-treatment of a polysymptomatic condition. Curr Med Res Opin. 2005;21(11):1785-1792. doi:10.1185/ $030079905 \times 65637$
6. Bei B, Manber R, Allen NB, Trinder J, Wiley JF. Too long, too short, or too variable? Sleep intraindividual variability and its associations with perceived sleep quality and mood in adolescents during naturalistically unconstrained sleep. Sleep. 2017;40:zsw067.

7. Sofi F, Cesari F, Casini A, Macchi C, Abbate R, Gensini GF. Insomnia and risk of cardiovascular disease: a meta-analysis. Eur J Prev Cardiol. 2014;21(1):57-64. doi:10.1177/2047487312460020

8. Meisinger C, Heier M, Löwel H, Schneider A, Döring A. Sleep duration and sleep complaints and risk of myocardial infarction in middle-aged men and women from the general population: the MONICA/KORA Augsburg cohort study. Sleep. 2007;30 (9):1121-1127. doi:10.1093/sleep/30.9.1121

9. Meier-Ewert HK, Ridker PM, Rifai N, et al. Effect of sleep loss on $\mathrm{C}$-reactive protein, an inflammatory marker of cardiovascular risk. J Am Coll Cardiol. 2004;43(4):678-683. doi:10.1016/j.jacc.2003.07.050

10. Kripke DF, Garfinkel L, Wingard DL, Klauber MR, Marler MR. Mortality associated with sleep duration and insomnia. Arch Gen Psychiatry. 2002;59:131-136. doi:10.1001/archpsyc.59.2.131

11. Xiang YT, Ma X, Cai ZJ, et al. The prevalence of insomnia, its sociodemographic and clinical correlates, and treatment in rural and urban regions of Beijing, China: a general population-based survey. Sleep. 2008;31:1655-1662. doi:10.1093/sleep/31.12.1655

12. Taylor DJ, Pruiksma KE, Hale WJ, et al. Prevalence, correlates, and predictors of insomnia in the US army prior to deployment. Sleep. 2016;39:1795-1806. doi:10.5665/sleep.6156

13. Liang T, Munro HM, Hargreaves MK, Steinwandel MD, Blot WJ, Buchowski MS. Patterns and correlates of sleep duration in the Southern cohort community study. Sleep Med. 2020;75:459-467. doi:10.1016/j.sleep.2020.09.004

14. Hughes RG, Rogers AE. Are you tired? Am J Nurs. 2004;104:36-38. doi:10.1097/00000446-200403000-00017

15. Chaiard J, Deeluea J, Suksatit B, Songkham W, Inta N. Short sleep duration among Thai nurses: influences on fatigue, daytime sleepiness, and occupational errors. J Occup Health. 2018;60:348-355. doi:10.1539/joh.2017-0258-OA

16. Chaiard J, Deeluea J, Suksatit B, Songkham W, Inta N, Stone TE. Sleep disturbances and related factors among nurses. Nurs Health Sci. 2019;21(4):470-478. doi:10.1111/nhs.12626

17. Silva-Costa A, Griep RH, Rotenberg L, Cajochen C. Associations of a short sleep duration, insufficient sleep, and insomnia with self-rated health among nurses. PLoS One. 2015;10(5):e0126844. doi:10.1371/ journal.pone.0126844

18. An F-R, Qi Y-K, Zeng J-Y, et al. Prevalence of insomnia, its demographic correlates, and treatment in nurses working in Chinese psychiatric and general hospitals. Perspect Psychiatr Care. 2016;52:88-94. doi:10.1111/ppc.12103

19. Zhou H, Han X, Zhang J, et al. Job satisfaction and associated factors among medical staff in tertiary public hospitals: results from a National Cross-Sectional Survey in China. Int $J$ Environ Res Public Health. 2018;15(7):1528. doi:10.3390/ijerph15071528

20. Richter D, Krämer MD, Tang NKY, Montgomery-Downs HE, Lemola S. Long-term effects of pregnancy and childbirth on sleep satisfaction and duration of first-time and experienced mothers and fathers. Sleep. 2019;42(4):42. doi:10.1093/sleep/zsz015

21. Streiner DL, Norman GR. Selecting the Items; Health Measurement Scales: A Practical Guide to Their Development and Use. Oxford: Oxford University Press; 2003.

22. Ohayon MM, Chen MC, Bixler E, et al. A provisional tool for the measurement of sleep satisfaction. Sleep Health. 2018;4(1):6-12. doi:10.1016/j.sleh.2017.11.002

23. Adler NE, Newman K. Socioeconomic disparities in health: pathways and policies. Health Aff. 2002;21(2):60-76. doi:10.1377/ hlthaff.21.2.60

24. Luckhaupt SE, Tak S, Calvert GM. The prevalence of short sleep duration by industry and occupation in the national health interview survey. Sleep. 2010;33(2):149-159. doi:10.1093/sleep/33.2.149 


\section{Publish your work in this journal}

Risk Management and Healthcare Policy is an international, peerreviewed, open access journal focusing on all aspects of public health, policy, and preventative measures to promote good health and improve morbidity and mortality in the population. The journal welcomes submitted papers covering original research, basic science, clinical \& epidemiological studies, reviews and evaluations, guidelines, expert opinion and commentary, case reports and extended reports. The manuscript management system is completely online and includes a very quick and fair peer-review system, which is all easy to use. Visit http://www.dovepress.com/testimonials.php to read real quotes from published authors.

Submit your manuscript here: https://www.dovepress.com/risk-management-and-healthcare-policy-journal 